\title{
Lhermitte-Duclos disease
}

INSERM

\section{Source}

INSERM. (1999). Orphanet: an online rare disease and orphan drug data base. Lhermitte-

Duclos disease. ORPHA:65285

Lhermitte-Duclos disease (LDD) is a very rare disorder characterized by abnormal

development and enlargement of the cerebellum, and an increased intracranial pressure. 